\title{
Students' perception of online learning during the COVID-19 pandemic: a survey study of Polish medical students
}

\section{Michał Bączek ( $\square$ michal.baczek@ujk.edu.pl)}

Institute of Medical Sciences, Jan Kochanowski University in Kielce, Kielce, Poland https://orcid.org/0000-0002-7652-2759

\section{Michalina Zagańczyk-Bączek}

Institute of Medical Sciences, Jan Kochanowski University in Kielce, Kielce, Poland

\section{Monika Szpringer}

Institute of Medical Sciences, Jan Kochanowski University in Kielce, Kielce, Poland

\section{Andrzej Jaroszyński}

Institute of Medical Sciences, Jan Kochanowski University in Kielce, Kielce, Poland

\section{Beata Wożakowska-Kapłon}

Institute of Medical Sciences, Jan Kochanowski University in Kielce, Kielce, Poland

\section{Research Article}

Keywords: online learning, e-learning, COVID-19, pandemic, skills, knowledge

Posted Date: July 14th, 2020

DOl: https://doi.org/10.21203/rs.3.rs-41178/v1

License: (1) This work is licensed under a Creative Commons Attribution 4.0 International License.

Read Full License

Version of Record: A version of this preprint was published at Medicine on February 19th, 2021. See the published version at https://doi.org/10.1097/MD.0000000000024821. 


\section{Abstract}

Background The COVID-19 pandemic has disrupted teaching in a variety of institutions, especially in medical schools. Electronic learning (e-learning) became the core method of teaching the curriculum during the pandemic. After eight weeks of only online learning, a survey was conducted to investigate perception of this type of learning amongst medical students.

Methods A survey was conducted by distributing an online questionnaire to Polish medical students. Data gathered from the survey was analyzed with routine statistical software.

Results 804 students answered the questionnaire. According to respondents' answers, the main advantages of online learning were the ability to stay at home (69\%), continuous access to online materials $(69 \%)$, learning at your own pace $(64 \%)$, and comfortable surroundings (54\%). The majority of respondents chose lack of interactions with patients $(70 \%)$ and technical problems with IT equipment $(54 \%)$ as the main disadvantages. There was no statistical difference between face-to-face and online learning in terms of opinions on the ability of the learning method to increase knowledge $(p=.46)$. Elearning was considered less effective than face-to-face learning in terms of increasing skills $(p<.001)$ and social competences $(p<.001)$. Students assessed that they were less active during online classes compared to traditional classes $(p<.001)$. E-learning was rated as enjoyable by $73 \%$ of respondents.

Conclusions E-learning is a powerful tool for teaching medical students. However, successful implementation of online learning into the curriculum requires a well thought-out strategy and a more active approach.

\section{Background}

The COVID-19 pandemic has disrupted teaching in a variety of institutions, especially in medical schools. In many countries, including Poland, typical face-to-face classes had to be suspended to ensure the safety of students, lecturers, and patients. To minimize the impact of lockdown, medical schools had to find another approach to teach medical students. Fortunately, current technology enabled electronic learning (e-learning) to be the core method of teaching the curriculum during the COVID-19 pandemic.

E-learning is defined as using information technology to improve the quality of education[1]. Currently, online teaching is commonly used in the training of undergraduates-not as a sole method, but combined with the traditional teacher-led approach[2,3]. The success of e-learning depends on many factors, including accessibility, usage of appropriate methods, course content, and assessment criteria. E-learning, like any method of teaching, has its advantages and disadvantages for both students and teachers. Besides the epidemiological benefits of e-learning during the COVID-19 pandemic, other benefits worth mentioning include increased convenience, access to resources regardless of location and time, and reduction of costs and air pollution, e.g. carbon dioxide emission because of the reduction in traffic[4-7]. 
Online classes also have limitations, including problems with internet access, poor internet connection quality, and insufficient digital skills of the respondents. Some benefits such as time flexibility can also bea limitation, especially for students who have difficulties with self-discipline[8-11].

After eight weeks of only online learning with no face-to-face learning, we decided to analyze medical students' perception of this teaching approach.

\section{Methods}

On March $20^{\text {th }}, 2020$, the Polish government declared a state of epidemic emergency, which resulted in the suspension of face-to-face learning in medical universities. All universities were obliged to conduct solely e-learning. After eight weeks of only online learning, an anonymous questionnaire was distributed to Polish medical students. The questionnaire was accessed online. There were no exclusion criteria. Each student was allowed to complete the questionnaire once. All respondents were fully informed about the objectives of the study and agreed to voluntarily participate. A total of 804 students participated in this study.

\section{Questionnaire}

The questionnaire consisted of four parts.

In the first part of the survey, students were asked to enter their demographic details (age, gender, year of study), describe their IT skills, and state whether they had previously participated in any online courses.

In the second part, respondents were given six sets of options regarding the advantages and disadvantages of e-learning, from which they could choose as many as were true for them.

In the third part, respondents had to compare, using the Likert scale[12] $(1=$ definitely ineffective, $5=$ definitely effective), face-to-face learning with online learning in terms of ability to master learning objectives (knowledge, clinical skills and social competences). Students were also asked to rate their activity during classes ( 1 = extremely inactive, 5 = extremely active).

In the last part, students were asked to rate the level of acceptance of online classes using the Likert scale from 1 to 5 ( 1 = extremely unenjoyable, 5 = extremely enjoyable) .

Because there is a noticeable difference between the amount of clinical classes from years 1-3 and 4-6 at medical school, we compared answers between these two groups of students.

\section{Statistical analysis}

The data was analyzed with the Statistica 13.3 (StatSoft, Inc., Tulsa, OK, USA) statistical software. Advantages, disadvantages, and level of acceptance of e-learning were analyzed using descriptive 
statistics. The non-parametric Wilcoxon signed-rank test was used to compare opinions on face-to-face and online learning. The Chi-square and Mann-Whitney tests were used to compare answers between less and more advanced students. $\mathrm{P}<.05$ was considered statistically significant.

\section{Results}

\section{Characteristics of respondents}

The characteristics of the medical students are shown in Table 1. Among the 804 students, $233(29 \%)$ were males and $571(71 \%)$ were females. The age of the students ranged from 18 to $39(M=22.66, \mathrm{SD}=$ 2.15). A total of $318(40 \%)$ students had previous experience with e-learning, whereas $486(60 \%)$ had no experience. A total of 451 (56\%) respondents described their IT skills as good, 337 (42\%) as moderate, and $16(2 \%)$ as poor.

Table 1 Characteristics of the study population $(n=804)$. 


\begin{tabular}{|lc|}
\hline Variables & $\mathrm{n}(\%)$ \\
\hline Gender & $233(29 \%)$ \\
\hline Male & $571(71 \%)$ \\
\hline Female & $130(16 \%)$ \\
\hline Age, y & $670(83 \%)$ \\
\hline $18-20$ & $4(1 \%)$ \\
\hline $21-30$ & $140(17 \%)$ \\
\hline $31-39$ & $121(15 \%)$ \\
\hline Year in medical school \\
\hline $1^{\text {st }}$ & $167(21 \%)$ \\
\hline $2^{\text {nd }}$ & $168(21 \%)$ \\
\hline $3^{\text {rd }}$ & $133(17 \%)$ \\
\hline $4^{\text {th }}$ & $75(9 \%)$ \\
\hline $5^{\text {th }}$ & $486(60 \%)$ \\
\hline $6^{\text {th }}$ & $318(40 \%)$ \\
\hline Previous experience in elearning \\
\hline Yes & \\
\hline No & \\
\hline IT skills & \\
\hline High & \\
\hline Moderate & \\
\hline Low & \\
\hline
\end{tabular}

\section{Advantages and disadvantages of e-learning}

The most frequent advantages of e-learning chosen by respondents were the ability to stay at home (69\%), continuous access to online materials (69\%), the opportunity to learn at your own pace (64\%), and comfortable surroundings (54\%). The majority of respondents chose lack of interactions with patients (70\%) and technical problems with IT equipment (54\%) as the main disadvantages (Table 2). Students in 
the first three years of studies more often chose technical problems with IT equipment $(p=.003)$, lack of self-discipline $(p<.001)$, and social isolation $(p=.008)$ as e-learning disadvantages, while students in their $4^{\text {th }}-6^{\text {th }}$ year of study more often chose lack of interaction with patients $(p<.001)$.

Table 2. Advantages and disadvantages of e-learning.

\begin{tabular}{|c|c|c|c|c|}
\hline \multirow[t]{2}{*}{ Variables } & $\begin{array}{l}\text { Years of studies } \\
1-3\end{array}$ & $\begin{array}{l}\text { Years of studies } \\
4-6\end{array}$ & \multirow{2}{*}{$p$} & \multirow[t]{2}{*}{$\begin{array}{l}\text { Total } n=804 \\
(100 \%)\end{array}$} \\
\hline & $\begin{array}{l}\mathrm{n}=428 \\
(53.23 \%)\end{array}$ & $\mathrm{n}=376(46.76 \%)$ & & \\
\hline \multicolumn{5}{|l|}{ Advantages of online learning } \\
\hline Access to online materials & $292(68 \%)$ & $260(69 \%)$ & .77 & $552(69 \%)$ \\
\hline Learning on your own pace & $273(64 \%)$ & $239(64 \%)$ & .95 & $512(64 \%)$ \\
\hline Ability to stay at home & $287(67 \%)$ & $271(72 \%)$ & .12 & $558(69 \%)$ \\
\hline Classes interactivity & $13(3 \%)$ & $22(6 \%)$ & .05 & $33(4 \%)$ \\
\hline Ability to record a meeting & $98(23 \%)$ & $67(18 \%)$ & .07 & $165(21 \%)$ \\
\hline Comfortable surrounding & $219(51 \%)$ & $215(57 \%)$ & .08 & $434(54 \%)$ \\
\hline \multicolumn{5}{|c|}{ Disadvantages of online learning } \\
\hline $\begin{array}{l}\text { Reduced interaction with the } \\
\text { teacher }\end{array}$ & 200 (47\%) & $163(43 \%)$ & .33 & $363(45 \%)$ \\
\hline Technical problems & $252(59 \%)$ & $183(49 \%)$ & .003 & $435(54 \%)$ \\
\hline $\begin{array}{l}\text { Lack of interactions with } \\
\text { patients }\end{array}$ & $230(54 \%)$ & $336(90 \%)$ & $<.001$ & $566(70 \%)$ \\
\hline $\begin{array}{l}\text { Poor learning conditions at } \\
\text { home }\end{array}$ & $75(18 \%)$ & $49(13 \%)$ & .07 & $124(15 \%)$ \\
\hline Lack of self-discipline & $208(49 \%)$ & $120(32 \%)$ & $<.001$ & $328(41 \%)$ \\
\hline Social isolation & 189 (44\%) & 132 (35\%) & .008 & 321 (40\%) \\
\hline
\end{tabular}

\section{Comparison between face-to-face and online learning}

There was no statistical difference between face-to-face $(M=3.23)$ and online learning $(M=3.27)$ in terms of opinions on the ability of the learning method to increase knowledge $(p=.46)$. E-learning was considered less effective than face-to-face learning in terms of increasing skills $(M=2.03, M=4.3$, respectively) ( $p<.001)$ and social competences $(M=2.03, M=4.2$, respectively) $(p<.001)$ (Figure 1$)$. 
Students assessed that they were less active during online classes $(M=2.72)$ compared to traditional classes $(M=3.82)(p<.001)$ (Figure 2).

\section{Acceptance of e-learning}

A total of $589(73 \%)$ respondents rated e-learning as enjoyable. Of these, $125(15 \%)$ found it extremely enjoyable, 237 (29\%) found it very enjoyable, and 227 (28\%) found it somewhat enjoyable. A total of 214 (27\%) students did not enjoy online learning. Of these, 80 (10\%) students found it extremely unenjoyable and $134(17 \%)$ very unenjoyable (Figure 3$)$. There was no statistically significant difference between answers given by students in the first three years of studies and those more advanced $(p=.63)$. There was no statistical difference between female and male students $(p=.46)$.

\section{Discussion}

In this survey study, we evaluated Polish medical students' perception of online learning during the COVID-19 pandemic.

Ease of access to educational materials and the ability to choose the time and place to study were shown as the strongest advantages of online learning among respondents in our survey. Remote access is of particular importance during the COVID-19 pandemic, but it can also reduce the cost of accommodation and transportation in other settings[13,14]. E-learning enables learning materials to be quickly delivered to students, standardized, and if needed, updated[15]. Content can be delivered to students using two different approaches: self-directed and instructor-led learning. Self-directed e-learning allows the learner to manage his activity independently. Recent findings by Peine et al. showed that self-directed e-learning can outperform traditional face-to-face learning[16].

E-learning is not without its disadvantages. The main problem for respondents in our survey, especially those in their $4^{\text {th }}$ to $6^{\text {th }}$ year of study, was lack of interaction with patients. Learning from real patients in a clinical setting is crucial for medical education and it cannot be fully replaced with distance learning[17]. To some extent, a solution to this issue could be the use of virtual patients (VPs). VPs are designed to simulate real-life clinical scenarios and they enable the learner to prepare him/herself before a real patient encounter[18].

Surprisingly, over $60 \%$ of the respondents in our survey had never experienced any form of e-learning before the COVID-19 pandemic, which might be the reason why technical issues were the second major disadvantage of e-learning in this study. E-learning requires a reliable internet connection and the necessary hardware and software[19,20]. Both students and teachers must be familiar with the equipment and they should receive technical support and guidance from the IT department before and during an online course. Self-learning requires the student to maintain self-discipline, which can be difficult without direct supervision from the teacher. Poor interaction between learners and facilitators, and a lack of clarity of the purpose and goals of the learning can impede the learning process[21,22]. 
Stacey and Gerbic advocated that students' maturity might increase their degree of self-discipline[23], which is consistent with findings in our study.

Our study group assessed that e-learning enabled them to increase their knowledge to the same extent as traditional learning. However, in their opinion, e-learning is definitely less effective in terms of increasing their clinical and social skills. E-learning to teach clinical skills is most effective when combined with traditional classes. Instead of using text-based materials, video instruction seems to be superior in teaching practical skills[24] and it fits with Peyton's four-step skill acquisition approach[25]. In this model, the teacher conducts a silent demonstration, then he repeats the procedure, this time describing all necessary sub-steps (deconstruction). Following this, the student has to explain each sub-step while the teacher follows the student's instructions (comprehension). The last step is performance, where the student performs the complete skill while he or she describes it.

An interesting solution for improving social skills is the use of remote standardized patients (RSPs), who communicate with students via the internet. RSPs can not only portray a specific clinical situation, but they also assess the learner and provide real-time feedback. Langenau et al. studied the use of RSPs and Skype and their effects on residents' social skills. In their study, $90 \%$ of participants agreed that this format was effective in teaching communication skills[26].

We found it interesting that respondents assessed that they were less active during e-learning than during traditional classes. One of the reasons could be the lack of an interactive approach when developing elearning courses. Only $4 \%$ of the respondents chose class interactivity as an advantage of e-learning during the COVID-19 pandemic. E-learning methods that are less interactive are viewed less favorably[27]. There are different ways to boost the interactivity of online learning. One new and promising method is gamification, in which "game design elements are used in non-game contexts"[28]. In a systematic review conducted by Hamari et al., gamification has been proven to be effective in many fields, especially in education[29]. A different approach could be social and collaborative learning. This technique allows students to socially interact with each other as well as instructors. They can work together to share ideas and expand their knowledge in an open forum. In a study by Bergl et al., the majority of residents assessed that Twitter enhanced their education [30]. Another technique worth mentioning is branching scenarios, in which students get the opportunity to test their skills in a practical setting. This form of learning requires the learner to make a decision and then present the consequences. Each decision produces new challenges and more choices. This technique is associated with higher learning outcomes, mostly regarding increasing knowledge and clinical reasoning [31].

\section{Conclusions}

This study showed that e-learning is a valuable method of teaching medical students. In the opinion of the respondents in our survey, e-learning is effective in increasing knowledge and is highly accepted. However, it is important not to focus only on increasing knowledge, but also on clinical and social skills. E-learning should not only be based on the delivery of content, but students should be able to work with 
the materials and receive feedback. Successfully implementing online learning into the curriculum requires a well thought-out strategy and a more active approach.

\section{List Of Abbreviations}

E-learning: Electronic learning

VPs: Virtual patients

RSPs: Remote standardized patients

\section{Declarations}

\section{Ethics approval and consent to participate}

All participatns gave written consent, and the study was conducted in accordance with the Declaration of Helsinki, and approved by members of the Bioethics Committee of Jan Kochanowski University, Poland $(27 / 2020)$.

\section{Consent for publication}

Not applicable

\section{Availability of data and materials}

The datasets used and analyzed during the current study are available from the corresponding author on reasonable request

\section{Competing interests}

The authors declare that they have no competing interests

\section{Funding}

The project is supported under the program of the Minister of Science and Higher Education under the name "Regional Initiative of Excellence" in 2019-2022 project number: 024/RID/2018/19, financing amount: 11.999.000,00 PLN. The funding was used for payment of the fee.

\section{Authors' contributions}


MB had the original idea for the study, developed in collaboration with MZB. MB and BWK carried out preliminary data analysis. MB drafted the paper, with MS providing critical revisions and substantial writing and MZB, AJ, and BWK contributing to later drafts. All authors critically reviewed the final paper before submission. Authors read and approved the final manuscript.

\section{Acknowledgements}

Not applicable

\section{References}

1. Howlett D, Vincent T, Gainsborough N, Fairclough J, Taylor N, Vincent R. Integration of a case-based online module into an undergraduate curriculum: what is involved and what is effective? e-Learning. 2009;6(4):372-84.

2. Blissitt AM. Blended learning versus traditional lecture in introductory nursing pathophysiology courses. J Nurs Educ. 2016;55:227-230.

3. Sadeghi R, Sedaghat MM, Sha Ahmadi F. Comparison of the effect of lecture and blended teaching methods on students' learning and satisfaction. J Adv Med Educ Prof. 2014;2:146-150.

4. Gibbons A, Fairweather P. Computer-based instruction. In: Tobias S, Fletcher J (eds). Training \& Retraining: A Handbook for Business, Industry, Government, and the Military. New York: Macmillan Reference USA, 2000:410-42.

5. Rosenberg M. E-Learning: Strategies for Delivering Knowledge in the Digital Age. New York: McGrawHill, 2001.

6. Chumley-Jones HS, Dobbie A, Alford CL. Web-based learning: sound educational method or hype? A review of the evaluation literature. Acad Med. 2002;77 (10 suppl):S86-S93.

7. Horton W. Evaluating E-learning. Alexandria, VA: American Society for Training and Development, 2001.

8. Niebuhr V, Niebuhr B, Trumble J, Urbani M. Online faculty development for creating E-learning materials. Edu Health. 2014;27(3):255-61.

9. Dyrbye L, Cumyn A, Day H, Heflin M. A qualitative study of physicians' experiences with online learning in a master's degree program: benefits, challenges, and proposed solutions. Med Teach. 2009;31(2):e40-6.

10. Bediang G, Stoll B, Geissbuhler A, Klohn A, Stuckelberger A, Nko'o S, et al. Computer literacy and elearning perception in Cameroon: the case of Yaounde Faculty of Medicine and Biomedical Sciences. BMC Med Edu. 2013;13(57):1-8.

11. Attardi S, Rogers K. Design and implementation of an online systemic human anatomy course with laboratory. Anat Sci Educ. 2015;8:53-62.

12. Liker R. A technique for the measurement of attitudes. Archives of Psychology, 140, 1-55. 
13. Stain SC, Mitchell M, Belue R, Mosley V, Wherry S, Adams CZ et al. Objective assessment of videoconferenced lectures in a surgical clerkship. Am J Surg. 2005;189(1):81-4.

14. Amesse LS, Callendar E, Pfaff-Amesse T, Duke J, Herbert WNP. Evaluation of computer-aided strategies for teaching medical students prenatal ultrasound diagnostic skills. Med Educ Online. 2008;13:13.

15. Zehry, Khaled \& Halder, Neel \& Theodosiou, Louise. E-Learning in medical education in the United Kingdom. Procedia - Social and Behavioral Sciences 2011. 15:3163-3167.

16. Peine A, Kabino K, Spreckelsen C. Self-directed learning can outperform direct instruction in the course of a modern German medical curriculum - results of a mixed methods trial. BMC Med Educ. 2016 Jun 3;16:158.

17. Swanwick T. Understanding Medical Education : Evidence, Theory, and Practice. Chichester, West Sussex :Blackwell Pub., 2010.

18. Urresti-Gundlach, M., Tolks, D., Kiessling, C. et al. Do virtual patients prepare medical students for the real world? Development and application of a framework to compare a virtual patient collection with population data. BMC Med Educ 17, 174 (2017).

19. Frith $\mathrm{KH}$, Kee CC. The effect of communication on nursing student outcomes in a web-based course. J Nurs Educ. 2003;42(8):350-8.

20. Lu D-F, Lin Z-C, Li Y-J. Effects of a web-based course on nursing skills and knowledge learning. J Nurs Educ. 2009;48(2):70-7.

21. Docherty A, Sandhu H. Student-perceived barriers and facilitators to e-learning in continuing professional development in primary care. Educ Prim Care. 2006;17:343-53.

22. Gagnon M, Legare F, Labrecque M, Fremont P, Cauchon M, Desmartis MA. Perceived barriers to completing an e-learning program on evidence-based medicine. Inform Prim Care. 2007;15:83-91.

23. Stacey E, Gerbic P. Success factors for blended learning. Melbourne, Australia: ASCILITE; 2008.

24. Buch SV, Treschow FP, Svendsen JB, Worm BS. Video- or text-based e-learning when teaching clinical procedures? A randomized controlled trial. Adv Med Educ Pract. 2014 Aug 16;5:257-62.

25. Walker M, Peyton JWR: Teaching in theatre. Teaching and learning in medical practice. Edited by: Rickmansworth JWRP. 1998, UK: Manticore Europe limited, 171-180.

26. Langenau E, Kachur E, Horber D. Web-based objective structured clinical examination with remote standardized patients and Skype: resident experience. Patient Educ Councs. 2014 Jul;96(1):55-62.

27. Cook D, Steinert Y. Online learning for faculty development: a review of the literature. Med Teach. 2013;35(11):930-7.

28. Deterding S, Dixon D, Khaled R, Nacke L. From game design elements to gamefulness; Proceedings of the 15th International Academic MindTrek Conference on Envisioning Future Media Environments - MindTrek'11; New York: ACM Press 9; 2011.

29. Hamari J, Koivisto J, Sarsa H. Does gamification work? - a literature review of empirical studies on gamification; 2014 47th Hawaii International Conference on System Sciences; Finland: IEEE; 2014. 
pp. 3025-34

30. Bergl PA, Narang A, Arora VM. Maintaining a Twitter feed to advance an internal medicine residency program's educational mission. JMIR Med Educ. 2015;1:e5.

31. Cook, David A. MD, MHPE; Erwin, Patricia J. MLS; Triola, Marc M. MD Computerized Virtual Patients in Health Professions Education: A Systematic Review and Meta-Analysis, Academic Medicine:

October 2010 - Volume 85 - Issue 10 - p 1589-1602.

\section{Figures}

(a)

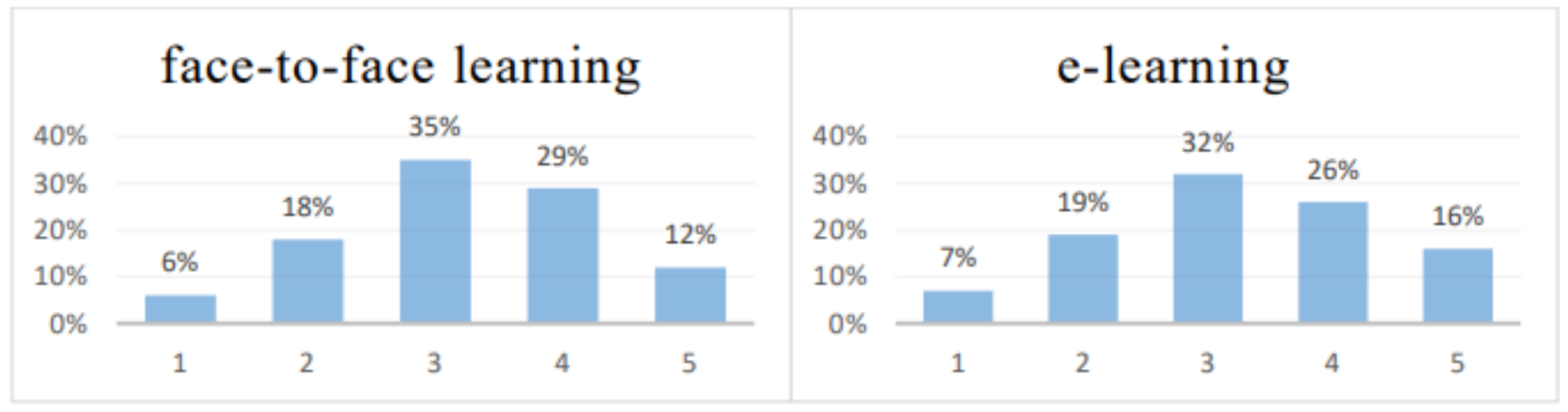

(b)

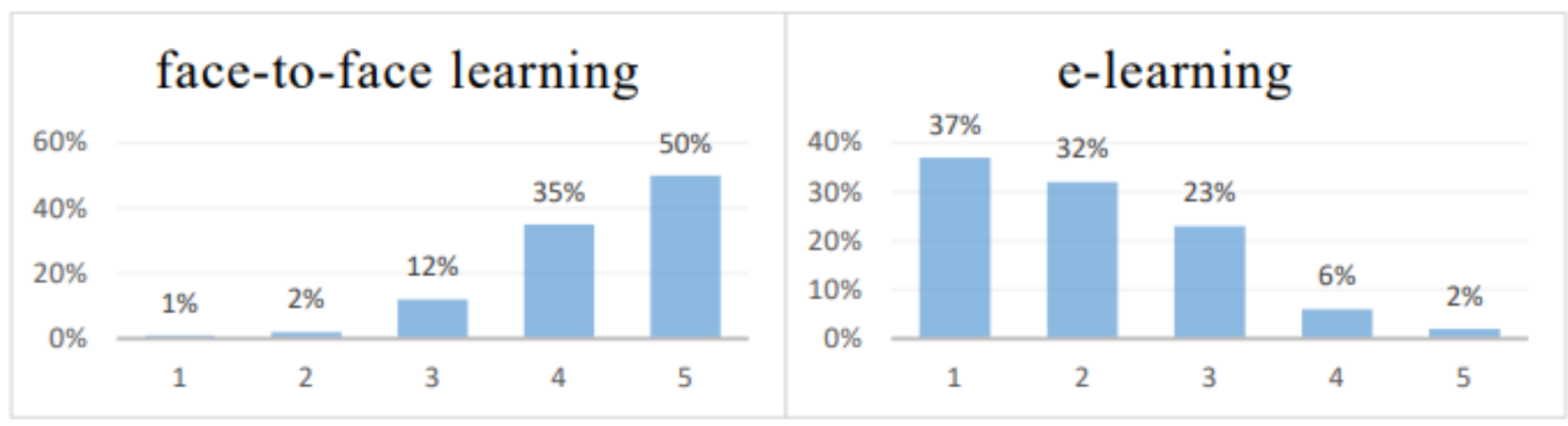

(c)

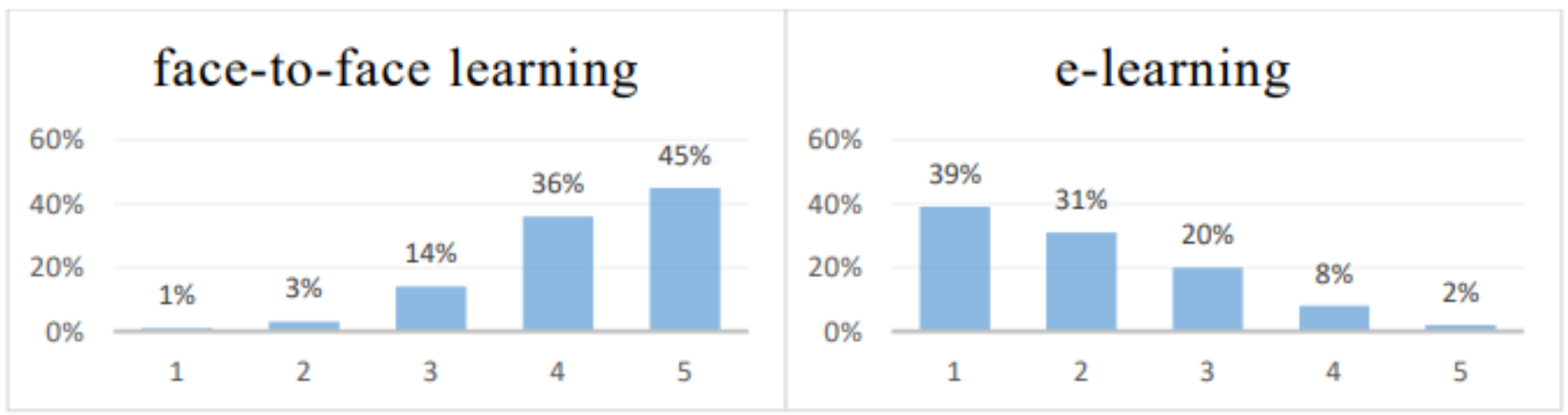

Figure 1 
Students' perception on the ability to increase knowledge (a), clinical skills (b) and social skills (c) during face-to-face and e-learning. Responders used the Likert scale where $1=$ definitely ineffective, $5=$ definitely effective.
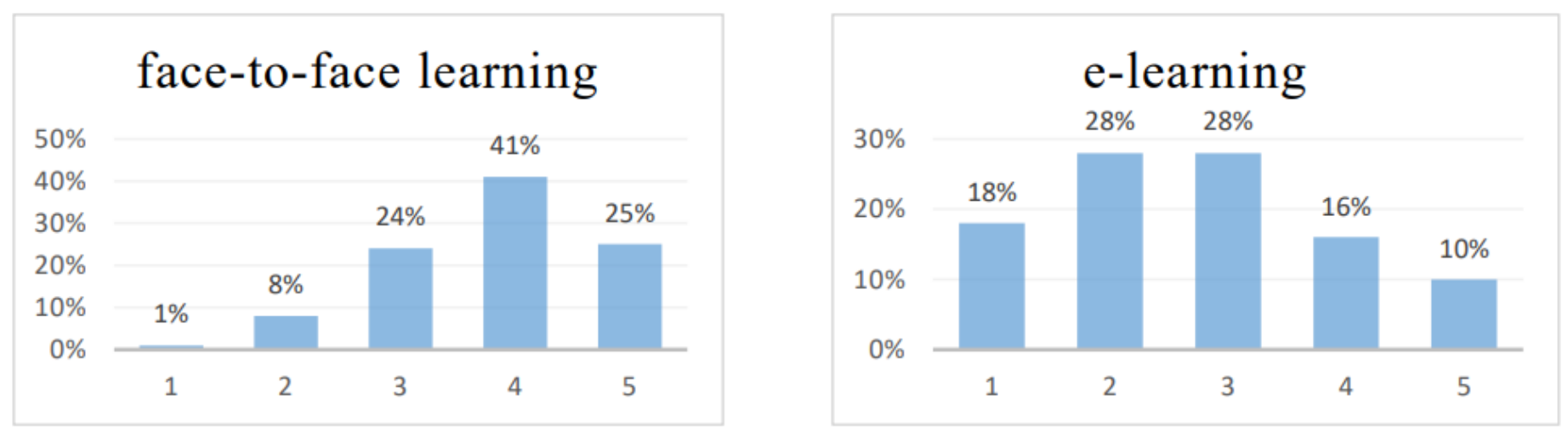

Figure 2

Students activity during face-to-face and e-learning, where 1 = extremely inactive, 5 = extremely active.

\begin{tabular}{|c|c|c|c|c|c|}
\hline \multicolumn{6}{|l|}{$35.00 \%$} \\
\hline $30.00 \%$ & & & $28.23 \%$ & $29.48 \%$ & \\
\hline \multicolumn{6}{|l|}{$25.00 \%$} \\
\hline $20.00 \%$ & & $16.67 \%$ & & & $15.55 \%$ \\
\hline \multicolumn{6}{|l|}{$15.00 \%$} \\
\hline \multicolumn{6}{|l|}{$10.00 \%$} \\
\hline \multicolumn{6}{|l|}{$5.00 \%$} \\
\hline \multicolumn{6}{|l|}{$0.00 \%$} \\
\hline & $\begin{array}{c}\text { extremely } \\
\text { unenjoyable }\end{array}$ & very unenjoyable & $\begin{array}{l}\text { somewhat } \\
\text { enjoyable }\end{array}$ & very enjoyable & $\begin{array}{l}\text { extremely } \\
\text { enjoyable }\end{array}$ \\
\hline
\end{tabular}

\section{Figure 3}

Level of acceptance of e-learning, where 1 = extremely unenjoyable, 5 = extremely enjoyable.

\section{Supplementary Files}


This is a list of supplementary files associated with this preprint. Click to download.

- Questionnaire.pdf 